\title{
HISTÓRIAS EM QUADRINHOS - HQS NA EDUCAÇÃO DO CAMPO EM ESCOLAS DE ASSENTAMENTO
}

\author{
Denis de Oliveira Silva ${ }^{1}$
}

\begin{abstract}
RESUMO: A construção de Histórias em Quadrinhos - HQs na escola de Educação do Campo (CALDART, 2004) é uma alternativa didática para trabalhar na sala de aula (VERGUEIRO, 2014), por meio de HQs que representem o sócio histórico das comunidades do Assentamento Agrícola de Vila Amazônia em Parintins, em Amazonas. O objetivo deste artigo é demonstrar a utilização de HQs na sala de aula de escolas de Assentamento, a partir da concepção da Educação do Campo, através das histórias orais dos comunitários que narraram histórias das comunidades, para as crianças na escola, as quais foram transformadas em HQs. A realização se deu por meio de um projeto de extensão do Instituto Federal de Educação, Ciência e Tecnologia do Amazonas, em duas escolas das comunidades: Mato Grosso e Santo Antônio do Tracajá. Como metodologia foi utilizada a fenomenologia (CERBONE, 2012) e a História Oral (ALBERTI, 2005). As crianças construíram HQs demonstrando as relações sócio-históricas de suas famílias e da comunidade.
\end{abstract}

Palavras-chave: Histórias em Quadrinhos - HQs. Educação do Campo. História local. Didática.

\section{STORIES IN COMICS - HQS IN THE FIELD EDUCATION IN SETTLEMENT SCHOOLS}

ABSTRACT: The construction of Cartoons in the school of Education of the Field (CALDART, 2004) it is a didactic alternative to work at the classroom (VERGUEIRO, 2014), through of Cartoons that represent the historical partner of the communities of the Agricultural Establishment of Amazonian Town in Parintins Am. The objective of this article is to demonstrate the use of Cartoons in the classroom of schools of Establishment, starting from the conception of the Education of the Field, through the oral histories of the community; they narrated the histories of the communities, for the children in the school, where they transformed them in histories in Cartoons. The accomplishment felt through a project of extension of the Federal Institute of Education, Science and Technology of Amazon, in two schools of the communities from Mato Grosso and Santo Antônio of Tracajá, as methodology the Phenomenology (CERBONE, 2012) and

\footnotetext{
${ }^{1}$ Doutorado em Educação em andamento na Universidade Estadual de Campinas, UNICAMP, Brasil.
} Mestrado em Educação em Ciências pela Universidade do Estado do Amazonas, UEA, Brasil. 
procedure the Oral History (ALBERTI, 2005). The children built the Cartoons demonstrating as relationships partner historical of their families and of the community.

Keywords: Cartoons. Education of the Field. History local. Didactic.

\section{HISTORIAS EN COMICS - HQS EN EDUCACIÓN DE CAMPO EN ESCUELAS DE ACUERDO}

RESUMEN: La construcción de Dibujo cómic en la escuela de Educación del Campo (CALDART, 2004) es una alternativa didáctica para trabajar en el aula (VERGUEIRO, 2014), a través de Dibujos cómics que representan al socio histórico de las comunidades del asentamiento Agrícola de Pueblo de Villa Amazonia en Parintins - Am. El objetivo de este artículo es demostrar el uso de Dibujo cómic en el aula de escuelas de asentamiento, a partir de la concepción de la Educación del Campo, a través de las historias orales de los comunitarios, ellos narraron las historias de las comunidades, para los niños en la escuela dónde ellos las transformaron en las historias en los Dibujos cómics. El logro se dio a través de un proyecto de extensión del Instituto Federal de Educación, Ciencia y tecnología de Amazona, en dos escuelas de las comunidades de Mato Grosso y Santo Antônio de Tracajá, como la metodología la Fenomenología (CERBONE, 2012) y procedimiento la Historia Oral (ALBERTI, 2005). Los niños construyeron los Dibujos cómics demostrando las relaciones socio históricas de sus familias y de la comunidad.

Palabras clave: Los Dibujos Cómic. La Educación del Campo. La Historia Local. Didáctico.

\section{Introdução}

A construção da Educação do Campo nas escolas é um processo em que os sujeitos que vivem e moram no território do campo no Brasil estão na luta por uma educação em que tenham experiências e vivências como pontos de partida para a compreensão do saber escolar e científico, de maneira diversificada. Nesse processo, por meio de uma concepção que possibilite criações para os sujeitos que estão tanto no espaço escolar quanto nas comunidades, em uma relação que precisa ser próxima, as metodologias didáticas necessitam ser pensadas e construídas no próprio local de existência, de tal forma que toda a escola participe da vida da localidade e que as pessoas que moram nela participem da vida da escola. 
A partir das discussões sobre Educação do Campo, desde 1998, estas construções estão crescendo no Brasil, por meio de práticas cotidianas nas escolas, através de seminários com iniciativas de movimentos sociais, que envolvem a participação dos sujeitos do campo em articulações com as secretárias de Educação. Isto se dá principalmente pela adesão de comunitários e de professores para construção de uma educação no e do Campo, que possa transformar a escola dissociada do contexto do campo em uma escola contextualizada e interligada com as peculiaridades em que cada escola está situada.

É um movimento em que a escola, seja e pertença ao campo, mas são desafios a serem superados, como: a permanência dos professores nas comunidades longínquas da sede do município; o currículo escolar que é construído para áreas urbanas, esquecendo-se de maneira proposital das áreas rurais; os recursos destinados para as escolas; as péssimas condições de prédios das escolas; a ausência de materiais didáticos; a formação de professores que não aborda os contextos da vida do campo.

Nessa concepção de educação percebemos a possibilidade de diálogos entre a Educação do Campo e as Histórias em Quadrinhos - HQs, trazendo as HQs como um recurso didático que represente as histórias das comunidades, através do conhecimento das crianças aprendidos no convívio comunitário e no contato com os mais velhos. Esse aprendizado das crianças no convívio com a comunidade se dá desde o nascimento, ao aprenderem a viver na localidade em contato direto com a natureza, com a cultura produzida e com a diversidade existente na Amazônia, vividas em terras de Assentamento. Destacam-se a relação com o lago que propicia o alimento do dia a dia; com a terra que concebe a mandioca, um material para fazer a farinha, o beiju, tucupi, pé de moleque e guloseimas que fazem parte da alimentação dos amazônidas que vivem no Assentamento de Vila Amazônia.

A relação das crianças com a natureza é de respeito e compreensão em que o sustento vem do cuidar, para que possam viver de maneira que não lhes falte o alimento e as aventuras de irem para o lago nadar, subir nas árvores, envolvimento em que a educação advém da cultura da família construída com o convívio com os mais velhos, principalmente com os avôs.

As diversidades sociais das comunidades do Assentamento são muitas, cada localidade possui sua história social, como em relação à formação do Assentamento, que se deu com a venda da terra por um político do estado do Pará, na qual até os dias 
de hoje, muitas pessoas moradoras das comunidades não entendem esse processo, pois, por bastante tempo a terra era deles e em outro momento na história não era mais, mas da União.

Em virtude disso pensou-se em trabalhar estas histórias nas salas de aula de duas comunidades do Assentamento, conhecidas como Mato Grosso e Santo Antônio do Tracajá, por meio de um projeto com duas turmas do 4을 ano e duas turmas do 5은 ano do ensino fundamental, em ambas as escolas. Eram turmas pequenas, em média 15 estudantes em cada, em razão de muitos pais tirarem as crianças da escola rural e levá-las para a cidade por acreditarem que a escola da cidade é melhor e que vai desenvolver a aprendizagem da criança mais rapidamente.

As crianças no início das atividades não conheciam as HQs, não possuíam a prática de leitura deste tipo de gênero textual, tinham dificuldades na leitura de imagens e dos textos escritos nos balões de diálogos dos personagens, ficavam em silêncio quando se conversava com elas no início das práticas de aulas com a HQs.

\section{A educação do campo e as histórias em quadrinhos (HQs): diálogos possíveis na sala de aula}

Os diálogos de metodologias de ensino e de aprendizagem são essenciais na construção da Educação do Campo nas escolas, como a transformação dos sujeitos que adentram os espaços escolares, por meio de uma educação que seja significativa para suas vidas.

A educação do campo surge com o propósito de educar a partir do local de vida dos sujeitos, com o ensino de temas interligados ao viver cotidiano, dialogando com o global, mas sempre o local sendo a essência e dando sentido ao mundo vivido pelos estudantes, como também a construção sócio-histórica das comunidades em que estão situadas as escolas.

O currículo destas escolas são muitas vezes urbanocêntrico (CORRÊA, 2005), constituído por propostas curriculares construídas para o contexto urbano, em que a criança aprende as primeiras letras para sair do campo, da floresta, que não dialoga com o contexto da escola, como existisse para si mesma, esquecendo de maneira intencional as realidades culturais, sociais das comunidades do Assentamento. No entanto, a busca de uma educação que seja dos sujeitos, que tenha o rosto, admitindo 
as peculiaridades das pessoas que vivem na área do assentamento, precisa ser construída através de diálogos com a associação de comunitários, com as lideranças, com os velhos das comunidades, esses sabem muito das suas realidades e como pode ser realizada a educação, que tenha a essência da localidade, onde a escola está localizada.

A efetivação da Educação Campo (CALDART, 2004), que não dialoga com as realidades das comunidades, ajuda no processo de esquecimento da memória social da construção sócio-histórica, transformando essas histórias cada vez mais sem importância para a vida comunitária. E em meio ao esquecimento das histórias de existência da construção das comunidades, a não valorização do que é realizado na comunidade, torna-se cada vez mais invisível o sentimento de pertencer a comunidade. Acontece uma relação de esconder o lugar onde vivem, de não valorizar o que os pais fazem para conseguir o sustento econômico e o alimento de suas famílias.

A escola não pode ser culpada por isso, mas tem ajudado as crianças e os adolescentes não valorizarem o que é seu, a essência, a riqueza de viver no ambiente amazônico de área de assentamento, as práticas culturais podem ser mais valorizadas por todos, os velhos de cada comunidade podem ser mais ouvidos e ter mais participação na construção social e educacional da escola e do espaço comunitário.

Arroyo (2004) evidencia que para a política e governos para a escola rural qualquer coisa serve, para mexer com a enxada não precisa de muitas letras. Esta percepção sobre a escola rural é encontrada com frequência nas escolas do campo, uma percepção sobre necessitar apenas dos professores e do barracão para sua existência. De acordo com palavras desse autor,

[...] imagem que sempre temos na academia, na política, nos governos é que para a escolinha rural qualquer coisa serve. Para mexer com a enxada não há necessidade de muitas letras. Para sobreviver com uns trocados, para não levar manta na feira, não há necessidade de muitas letras. Em nossa história domina a imagem de que a escola do campo tem que ser a escolinha rural das primeiras letras. A escolinha cai não cai, onde uma professora que quase não sabe ler ensina alguém a não saber quase ler (ARROYO, 2004, p. 71).

Essa característica da escola do campo precisar mudar, de uma educação desvalorizada, para uma educação de identidades construídas pelos sujeitos em processo participativo, onde, o contexto social e histórico apareça no cotidiano da 
escola, sendo o princípio norteador da pluralidade pedagógica, mencionada na Lei no 9.394, de 20 de dezembro de 1996.

Criar um movimento de construção de identidades da escola do campo, em que os estudantes sintam o pertencimento ao lugar de vida, percebam a cultura do lugar, rica de significados, onde existam diálogos com saberes escolares, científicos. Assim, para que processo de ensino e de aprendizagem seja significativo para a vida do aluno, perpassa pela escola conhecer o local de vida de seus atores, o que ocorre em seu entorno, conhecer as pessoas que fazem a localidade existir socialmente, culturalmente, economicamente por meio do trabalho. Que esse processo em que a cultura local adentra as salas de aula seja um olhar no qual os sujeitos escolares, professores, gestores vejam o que a comunidade realiza, e que muitas vezes a escola não valoriza ou não percebe e, nessa não percepção, a escola e comunidade distanciam-se uma da outra.

Nesta concepção de valorização e abordagem da história local para dentro da escola, perpassa pela participação da escola na vida da comunidade, uma relação mútua, em que as pessoas dessa comunidade sintam que a escola participa de suas vidas. Como exemplo, as idas e vindas da plantação são momentos essenciais para a criança, no aprendizado de saberes comunitários e científicos que a escola precisa aproveitar para fazer a transdisciplinaridade.

O viver nas duas comunidades pesquisadas é singular embora estejam no mesmo Assentamento. A comunidade do Mato Grosso possui esse nome por conta de que, quando se formou a comunidade a floresta era densa, muito fechada, em que os comunitários viviam em terras de várzea, ou seja, uma extensão de terra que alaga quando as águas do Rio Amazonas sobem em determinada época do ano. Outra versão para esse nome que ouvimos foi que existiam na fundação da comunidade muitas pessoas de outras regiões do país, como do estado do Mato Grosso.

Os comunitários contam que, em torno da década de 1970, a subida das águas foi grande, obrigando as pessoas a irem atrás de outra localidade para morarem, ocasião na qual encontraram o local em que vivem hoje, o qual se localiza na beira de um riacho na época da descida das águas, mas, na subida vira um lago, isso foi outro motivo que impulsionou esta mudança da comunidade de lugar.

O convívio social nas comunidades do Assentamento são relações de economia solidária, em que os comunitários ajudam um ao outro, fazendo trocas de utensílios 
necessários para a vivência, mas, que têm deixado de existir em várias localidades. 0 que atrapalha também é a falta de continuação dos estudos escolares nas comunidades, a falta de emprego, como a falta de incentivos para a agricultura, são fatores que levam aos afastamentos sociais e a mudança das pessoas para a zona urbana.

A construção do termo comunidades para muitos moradores do assentamento, se dá por passarem a viver em comum, compartilhando a existência de tudo no local de vida. Medeiros (2017, p. 34), aponta, três possibilidades, do surgimento do termo nas localidades rurais amazônidas:

\begin{abstract}
O termo comunidades rurais ou simplesmente comunidade, como falado por seus moradores, designa usualmente o local onde estão as casas de um povoado rural. As comunidades rurais começaram a surgir em Parintins a partir da década de 50 , com a contribuição de pelo menos três projetos históricos: o primeiro é dos missionários italianos do PIME, que consideravam a formação das comunidades uma estratégia de consolidação da religião católica no combate às outras formas de viver a religiosidade; 0 segundo projeto histórico é o de ribeirinhos, que tinham nesta formação social uma forma de identidade política também estratégica para facilitar o diálogo com o poder público na conquista de bens sociais relativos à saúde, educação, transporte e construção de estradas; Já o terceiro projeto histórico está ligado aos agentes pastorais da Igreja Católica motivados pela Teologia da Libertação a partir da influência do Concílio Vaticano II no Brasil e dos Encontros de Medelín (1968) e Puebla (1979).
\end{abstract}

A compreensão do sentido de comunidade é pensar que se formam em processos contínuos de viver com o outro, como organização para reivindicar direitos e principalmente o compartilhamento e trocas de utensílios pescados e plantados, são práticas cotidianas e familiares que constroem as comunidades na Amazônia, organizações que fortalecem os laços culturais e educacionais.

Há uma prática muito rica nas comunidades da Amazônia o chamado Puxirum, em que todos da comunidade combinavam para fazer o trabalho na terra do outro comunitário, com o sentimento de fraternidade, de ajudar o outro. Houve um momento, por influência capitalista, estas práticas diminuíram e dificilmente são vistas atualmente. Qualquer trabalho feito na terra do outro agora é cobrado, não existindo de fato o viver em comunidade, existente em outras épocas nessas localidades. 
Desta forma, a escola pode mobilizar essas vivências dos alunos nas aulas por meio da metodologia de ensino que emprega as histórias em quadrinhos, as quais entram na discussão para ajudar no fortalecimento do pertencimento, e que a escola torne-se mais próxima historicamente e socialmente das comunidades. Essa importância de inserir as HQs na vida das crianças, se justifica por possibilitar-lhes a compreensão de mundos imaginários, reais, em que se sintam autoras na criação de suas próprias histórias, introduzindo-as como narrativas gráficas, conforme Santos Neto e Silva (2015, p.11) as define:

As histórias em quadrinhos são narrativas gráficas constituídas por escrita e desenho, que exigem de seus leitores e leitoras interpretações visuais e verbais. Isso implica, para aqueles e aquelas que desejam trabalhar com elas, alfabetiza-se em sua linguagem no intuito de conhecer seus limites e possibilidades no trabalho educativo.

As crianças devem ser introduzidas na leitura e escrita de maneira lúdica, em que os professores estejam atentos ao universo da criança, para, a partir disso, ensinálas, por meio da escrita e das imagens, "impulsionando-as a lerem verbalmente e visualmente, inserindo a leitura de mundo, em que o mundo não é, ele está sendo" (FREIRE, 1996). Nesse processo inicial para a leitura da palavra, o gênero textual HQs dá essa oportunidade, em que alfabetizar a criança é um processo rico de linguagem, através do sócio-histórico, em que a interação com seu mundo cultural comunitário precisa dialogar com o saber escolarizado.

\section{Procedimentos metodológicos}

A construção deste artigo partiu de um projeto de extensão, baseado na abordagem Qualitativa, em que buscou a interação com os sujeitos participantes no local de realização da ação de extensão. Contou com a participação de duas estudantes do ensino Médio Integrado do Curso de Agropecuária, em que puderam associar os conhecimentos adquiridos no curso para compreender a vida das comunidades do Assentamento, percebendo a importância e significado da ciência para suas vivências, como para os sujeitos das comunidades.

As idas às comunidades se davam de duas maneiras, na comunidade do Mato Grosso, as viagens até a localidade era mais fácil por conta da proximidade da sede da cidade de Parintins, íamos todas as terças, durante o segundo semestre de 2017, 
utilizávamos a estrada do assentamento, o transporte utilizado era uma motocicleta, e levávamos em torno de 20 minutos para chegar à escola da comunidade. 0 primeiro passo da saída da cidade era a balsa que transporta as pessoas e mercadorias, um trajeto via fluvial levando aproximadamente 45 a 60 minutos. Na comunidade de Santo Antônio do Tracajá, utilizou-se a lancha institucional do IFAM Campus Parintins, com capacidades para 12 passageiros, o caminho se dava pelo Rio Amazonas, depois adentrávamos a área do Uaicurapá pelo rio Tracajá.

Teve-se como abordagem fenomenológica, construída com as crianças, com os pais e professores que nos deram a oportunidade de realizar a ação de extensão nas escolas do Mato Grosso e Santo Antônio do Tracajá. Retornar aos mundos vividos dos sujeitos mais velhos das comunidades, para que relembrem a percepção construída sobre o lugar de vida.

\footnotetext{
Esses imperativos de reencontrar, de redespertar e de retornar estão conectados ao fato de Merleau-Ponty levantar uma vez mais a questão justamente acerca do que é fenomenologia, uma vez que sua concepção de fenomenologia e seu chamado de "retorno" estão unidos. A fenomenologia facilita esse retorno e registra os resultados. Na verdade, a ideia de retornar, deter nossa atenção trazida de volta a algo agora negligenciado, é inerente a própria ideia de fenomenologia [...] (CERBONE, 2012, p. 159).
}

Nesse processo fenomenológico de desconstrução do que os estudantes, professores e comunitários possuem de não valorizar as suas próprias histórias vividas nas comunidades do Mato Grosso e Santo Antônio do Tracajá no Assentamento Agrícola, as quais as crianças precisam valorizar e construir outras histórias a partir delas e que o viver nessas localidades seja construído com a participação de todos em discussões que venham abordar o local em que moram.

A utilização da Fenomenologia deu suporte aos relatos dos comunitários, nos quais relembraram as histórias vividas por eles na trajetória de suas vidas, e com as crianças em conhecerem estas histórias não contadas anteriormente. Para o processo de falas e escutas utilizamos a História Oral para nos auxiliar em como proceder em campo com os sujeitos (ALBERTI, 2005), a qual nos oportunizou trazer para a escola, relatos dos velhos das comunidades por meio de suas histórias de vida e como surgiu o local em que vivem. 
A metodologia da História Oral possibilitou conhecer algumas histórias dos comunitários como da localidade, fazendo articulações entre as memórias coletivas e individuais.

\begin{abstract}
A História Oral produz narrativas orais, que são narrativas de memória. Essas, por sua vez, são narrativas de identidade na medida em que o entrevistado não apenas mostra como ele vê a si mesmo e o mundo, mas também como ele é visto por outro sujeito ou por uma coletividade. Nesse sentido, 'a dependência da memória, em vez de outros textos, é o que define e diferencia a história oral em relação a outros ramos da História [...] (SILVEIRA, 2007, p. 41).
\end{abstract}

Assim sendo, precisamos ser mais críticos no que tange ao significado que está por trás de memórias particulares coletadas pelo pesquisador em um trabalho envolvendo a História Oral.

\title{
A inserção das HQs na vida das crianças nas escolas do Assentamento
}

A construção coletiva da Educação do Campo é um processo de emancipação social e cultural que está sendo elaborada por meio de diálogos com setores populares, lideranças comunitárias, com os profissionais que fazem a educação escolar.

As relações entre comunidade e escola estão cada vez mais próximas para a realização de um processo de ocupação do latifúndio do saber (ARROYO, 2015), relações essas que iniciam com a percepção dos profissionais que estão na escola, em serem sensíveis ao chamar a comunidade para adentrar a escola, e que não estejam na escola apenas para buscar as crianças e participarem de reuniões de pais e mestres, mas serem inaudíveis, reuniões em que não são chamados para discutir o tipo de escola, de educação que querem que a escola construa. São convocados somente para ouvir reclamações, que as crianças têm dificuldades de aprendizagem, os pais vão à escola apenas para ouvir o que a escola possui para falar, em que pouco espaço é dispensado para os sujeitos da comunidade falarem, dialogarem com a escola.

O viver nas comunidades de Mato Grosso e Santo Antônio do Tracajá é parecido, e particularmente diverso e peculiar em cada localidade. Na comunidade do Mato Grosso, utiliza-se o transporte terrestre por meio da estrada do Assentamento de Vila Amazônia, enquanto na comunidade do Santo Antônio o transporte é fluvial. Ambas as comunidades vivem o processo de subida e descida das águas do Rio Amazonas, que 
inunda os lagos que circundam as comunidades, transformando o cotidiano e o modo de vida dos comunitários no decorrer dos períodos do ano.

O plantio de banana e de mandioca constitui-se nas culturas existentes nas duas comunidades, em que as crianças ajudam os pais e avós a cultivarem para o sustento e é feita a venda dos produtos nas comunidades e na cidade, trazendo as produções por vias terrestres e fluviais. A realização do cultivo dessas culturas acontece de maneira diária, em que as famílias vão para os chamados "roçados", plantam, cuidam, irrigam e colhem. Trabalho realizado muitas vezes de maneira braçal, com terçado, enxada, ancinho, pela utilização do fogo para queimar e limpar a terra para receber o que pretendem plantar.

As crianças ajudam aos pais nesse processo de trabalho com a terra, no qual todos da família participam. É uma agricultura de subsistência, baseada na agricultura familiar, e às vezes há uma espécie de puxirum, em que todos da comunidade se mobilizam para fazer o trabalho na terra de outra pessoa da comunidade, em troca apenas do bem coletivo, mas essas práticas hoje em dia estão escassas por conta da usurpação da força de trabalho que precisa ser paga com o dinheiro, o individualismo e a competição são fatores preponderantes em algumas ações nas comunidades. E para compreender estas e outras histórias, principalmente para que a escola trabalhe as histórias locais, pensou-se na utilização e criação de Histórias em Quadrinhos - HQs pelas crianças das escolas, conforme já referido.

A inserção das HQs na sala de aula foi um processo de construção coletiva com os estudantes, professores e pais ou responsáveis, foram encontros com o gestor da escola e com os professores para apresentação e discussão se aceitariam o projeto na escol, Vale salientar que nas duas escolas que realizamos o projeto fomos aceitos com alegria para trabalharmos, outro passo foi apresentar o projeto para os comunitários, falar da importância da construção do registro de suas próprias histórias e quanto às memórias das comunidades estão se perdendo, seja por falta de valorização cultural, pela falta de vontade das crianças em conhecer as histórias, e a escola por não valorizar e não trabalhar as histórias locais, políticas públicas que não acontecem para construir cidadania para o homem do campo.

A Base Nacional Comum Curricular (BNCC) indica que desde a Educação Infantil, a escola precisa trabalhar as memórias individuais e coletivas, apontando as histórias em quadrinhos, como recurso didático, na disciplina Língua Portuguesa, desde o 1ํ Ano 
do Ensino Fundamental. É considerada um meio importante para ser utilizado em aula, mas, infelizmente nas escolas em que trabalhamos, as crianças não conheciam este gênero textual, sendo que já se encontravam no 4으 e 5을 Anos do ensino fundamental. 0 recurso da fonte oral também foi utilizado, para conhecermos as histórias que construíram e constroem o lugar, este recurso também está contido na BNCC, que orienta sobre a necessidade de conhecer as histórias sobre a existência familiar e local em que estão vivendo (BRASIL, 2018).

O início da atividade nas escolas foi através de conversa com as crianças sobre se gostavam de desenho animado, assistiam filmes de super-heróis, liam HQs, responderam que sim para as duas afirmativas e para HQs falaram que não conheciam. Na comunidade do Mato Grosso, pela proximidade com a cidade, foi possível ir uma vez por semana na escola para desenvolver as atividades. Na primeira semana falamos dos principais super-heróis dos desenhos animados e foi um diálogo em que as crianças se expressaram, apresentamos algumas características dos personagens, elas iam concordando e discordando, expressaram pontos de vista como pensavam sobre cada desenho. Foi uma atividade que possibilitou trabalhar de maneira interdisciplinar, abordando Língua Portuguesa, História, Ciências e Artes, e que possibilitou perceber que estas histórias são muito ricas para articulação com o encontrado nas histórias e com suas vidas.

Na segunda semana, levamos as HQs para a sala de aula, para as crianças conhecerem as histórias, como do Homem de Ferro, Capitão América, Incrível Hulk, Zé Carioca, Turma da Mônica, Pato Donald, Pateta, Pantera Negra, Liga da Justiça, Batman, Super-homem. Fizemos um momento em que as crianças compartilharam as leituras, em que cada uma pôde expressar seu pensamento no momento coletivo, momentos esses praticados nas comunidades em forma de rodas de conversas à noite, em casas em que mulheres, crianças e homens reúnem-se para contarem histórias de vida e experiências sobre o cotidiano trabalhado na comunidade, como contar histórias de encantados que habitam os rios, as plantações, a estrada, a floresta.

Nessa interação social a educação acontece, a participação das crianças por meio da articulação verbal é uma atividade essencial para a aprendizagem da criança, a escola rural educava para o silêncio, em que a sala de aula perpassa o silêncio da não expressão espontânea da criança, entoando apenas a voz do professor. A Figura 1 mostra o registro de um momento importante de diálogos de interpretações textuais, a 
história em quadrinhos que se trabalhou nesta aula foi do Tio Patinhas, que traz a aventura de um povo nórdico de uma coletânea para incentivar a leitura de diferentes povos do mundo inteiro. Através dela, pode-se traçar um diálogo sobre o que íamos lendo na HQs e a vida de cada criança que vive nas comunidades do Mato Grosso e Santo Antônio do Tracajá.

Figura 1 - Leitura e interpretação de Hqs na sala de aula.

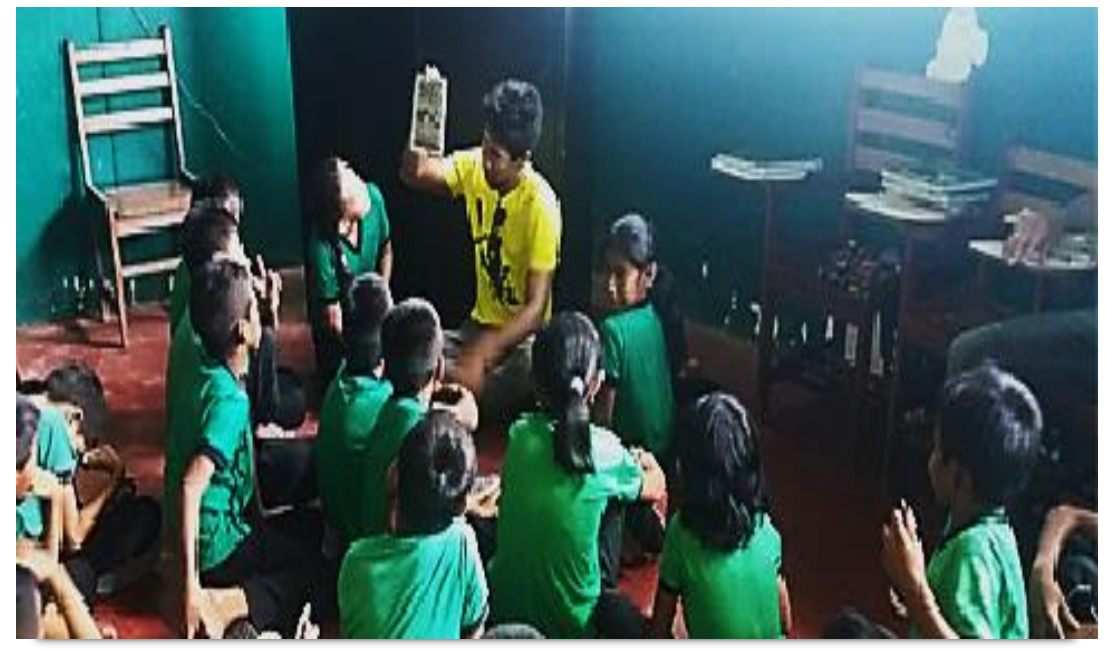

Fonte: Arquivo pessoal do autor (2017).

Antes de se fazer esta roda de leitura, foram feitas outras com as turmas, as crianças das duas escolas foram levadas para rodas de conversa com os velhos da comunidade que narraram a história da construção de cada localidade. Foi um momento de muita aprendizagem sobre suas próprias vidas em que as crianças, participaram bastante, ouvindo com atenção e perguntando, de maneira que seus olhos brilhavam de atenção como se a cada piscada um mundo se revelasse diante de suas vidas. Neste processo, relacionamos as histórias contadas pelos comunitários nas rodas de conversa com as rodas de leituras e fomos introduzindo diálogos em que as crianças foram relacionando com suas histórias.

A construção da prática didática na sala de aula das turmas do 4 으 e 5o anos do ensino fundamental foi um processo de diálogo interdisciplinar por meio das vivências e experiências dos estudantes junto com os pais e comunitários. Essa prática, que serve como meio didático para trabalhar de maneira interdisciplinar com as crianças, propiciou-lhes entender a importância de aprenderem a viver nos ambientes 
amazônicos, de maneira a aproveitarem os recursos naturais disponibilizados, recursos construídos pela ação do homem na natureza.

$\mathrm{Na}$ ação representada na Figura 1, apresentada anteriormente, trabalhamos com as crianças a leitura da HQs em roda de conversa, atividade na qual íamos lendo juntos, e cada página lida discutíamos sobre o que estava sendo apresentado na história. As crianças das duas escolas apresentaram dificuldades na leitura e escrita das palavras, sendo percebido que é pouco incentivada a prática de leitura, um processo concebido nessas escolas pelas crianças como uma prática dolorosa, uma forma de castigo, pois, muitas vezes, é incentivada pela própria escola quando estão agitadas e bagunçando, sendo colocadas para ler e treinar a leitura e o professor, posteriormente, as chama na sua mesa para avaliá-las com base nessa atividade que lhes foi atribuída como um castigo.

Nessa prática de roda de conversa, as crianças têm a oportunidade de praticar a leitura de maneira coletiva, refletindo juntas sobre o que acontece na HQs e, como ler também a arte visual possibilita que a criança aprenda ler de maneira divertida, estabelecem relações com o que assistem nos canais de TV, por exemplo. Como tivemos a oportunidade de trazer os desenhos animados por meio das HQs, observamos que contribuíram para problematizar as realidades sociais existentes na comunidade local e no mundo, como o problema de moradia, de água, de migrações, disputas de terra, como das águas e beiras dos rios que em muitos casos são tomadas como privadas pelos donos de sítio e fazendas, povos tradicionais e outros assuntos presentes na HQs que trabalhamos.

O processo das crianças conhecerem as HQs foi didático, em que cada criança levou para casa um exemplar para ler, e, uma semana depois, retornamos e foi possibilitado, a cada uma das crianças, que compartilhasse com a turma o que conheceu na leitura da HQs que levou para casa. Essa proposta objetivou construir uma prática de leitura e escrita de HQs pelas crianças das escolas pesquisadas e mostrounos uma necessidade de valorização cultural imaterial com o lugar em que vivem, como as construções sociais vividas nessas localidades. Observou-se ainda que as crianças não conhecem ou parece não valorizarem essa construção social do lugar, o que pode decorrer do saber escolar muitas vezes negar o currículo prescrito, que orienta para este diálogo da escola com a comunidade. 
Embora, as crianças tenham realizado as práticas de leitura de maneira coletiva, percebeu-se que há muitas dificuldades em compreender a leitura de imagens com as palavras escritas. Assim, inserir estas práticas no cotidiano da escola é necessário, pois, faz com que a criança perceba como ler as imagens que a cerca, como interpretá-las para que possa lutar pelo lugar de moradia, pode possibilitar uma educação que esteja integrada com suas realidades e culturas.

A Figura 2 mostra um dos estudantes construindo sua HQs, a partir de sua história de vida, a importância do ponto de partida para o estudante compreender que todo o ensino escolarizado precisa considerar as histórias de cada aluno no processo de aprendizagem significativa. Precisa consistir em uma ação de formação que busque a transformação individual e social, pensando e agindo localmente, mas sempre conectado com o global.

Figura 2 - Criança construindo HQs, a partir da sua história de vida.

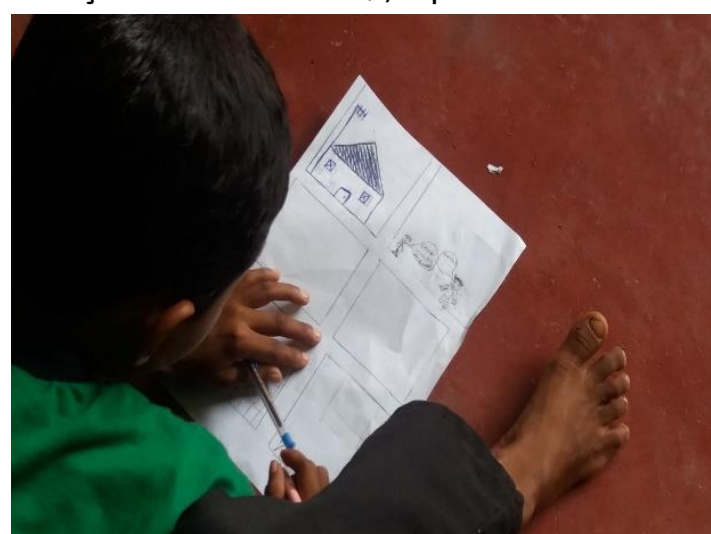

Fonte: Arquivo pessoal do autor (2017).

O estudante em atividade conforme mostrado pela Figura 2, no início das atividades não participava, falava sempre que iria fazer o que estava sendo pedido, mas, não fazia. Através da convivência e de atividades de leitura das HQs, conversas sobre suas vidas, visita do líder da comunidade para relatar a história local, esse aluno começou a participar e construir suas HQs, interagindo com os colegas, produzindo textos escritos e emitindo sua opinião quando estávamos dialogando sobre as temáticas das HQs.

Percebemos na Figura 2, a desenvoltura do estudante em construir sua HQs para contar sua história de vida, dando significância existencial ao mundo, narrando 
por si mesmo, processo esse que precisa ser valorizado nas escolas, em que os estudantes podem representar no papel o que pensam, sentem, o que vivem, em um registro de suas vidas contadas por eles mesmos.

A educação da criança que vive no Assentamento começa muito antes dela adentrar a escola, conhecimentos são aprendidos na convivência, no próprio contexto de existência que possibilita a criança, aprender com o outro, pensando na alteridade desde a infância. Essa educação possibilita viver, perceber, e construir o mundo a partir de si. A atividade mostrada na Figura 2 de construção de HQs possibilita que a criança entre em seu mundo, dando-lhe possibilidades de transpor seus olhares, como Merleau-Ponty (2014, p. 17), ajuda a visualizar:

\begin{abstract}
Pois se é certo que vejo minha mesa, que minha visão termina nela, que ela fixa e detém meu olhar com sua densidade insuperável, como também é certo que eu, sentado diante de minha mesa, ao pensar na ponte da Concórdia, não estou mais em meus pensamentos, mas na ponte da Concórdia; e que, finalmente, no horizonte de todas essas visões ou quasevisões está o próprio mundo que hábito, o mundo natural e o mundo histórico, com todos os vestígios humanos de que é feito - é certo também que esta certeza é combatida, desde que atento para ela, porquanto se trata de uma visão minha.
\end{abstract}

Ao construir sua história em quadrinhos nas imagens, a criança vai além do que vê no momento, precisa realizar um exercício de pensamento, refletir sobre o que sabe de si mesma e do mundo que está em si e no seu entorno, dando significado ao mundo do qual faz parte.

Nesse sentido, a criança precisa ser iniciada no processo de compreensão de seu mundo sócio-histórico para que se torne crítica exercendo sua cidadania e que ajude a transformar a realidade social de sua comunidade, como sua própria história enquanto sujeito, de maneira a alcançar seus propósitos ela precisa realizar exercícios de pensamento, problematizando seu local de vida, em diálogo com conhecimentos plurais que a escola trabalha na proposta curricular. O criar na escola do campo precisa ser uma fonte em que o professor perceba seu papel relevante na construção do conhecimento do aluno em suas aulas, abordando aspectos da vida do camponês que pesca, planta e colhe. Dessa maneira o professor precisa de todos os conhecimentos para fazer a vida do campo ser valorizada por todos, em defesa desse sentido, necessita-se construir metodologias didáticas que abordem uma educação do campo, que tenha sentido e significância para as crianças. 
Na Figura 3 está uma atividade que representa a comunidade e o cotidiano de um dos alunos, atividade essa que estava sendo desenvolvida pelo autor na representação da Figura 2. Trata-se de um momento essencial para a aprendizagem significativa que nasce na reflexão sobre seu próprio local de existência, dando possibilidades de registros sobre o cotidiano vivido.

Figura 3 - Desenho representativo do local de vida do estudante.

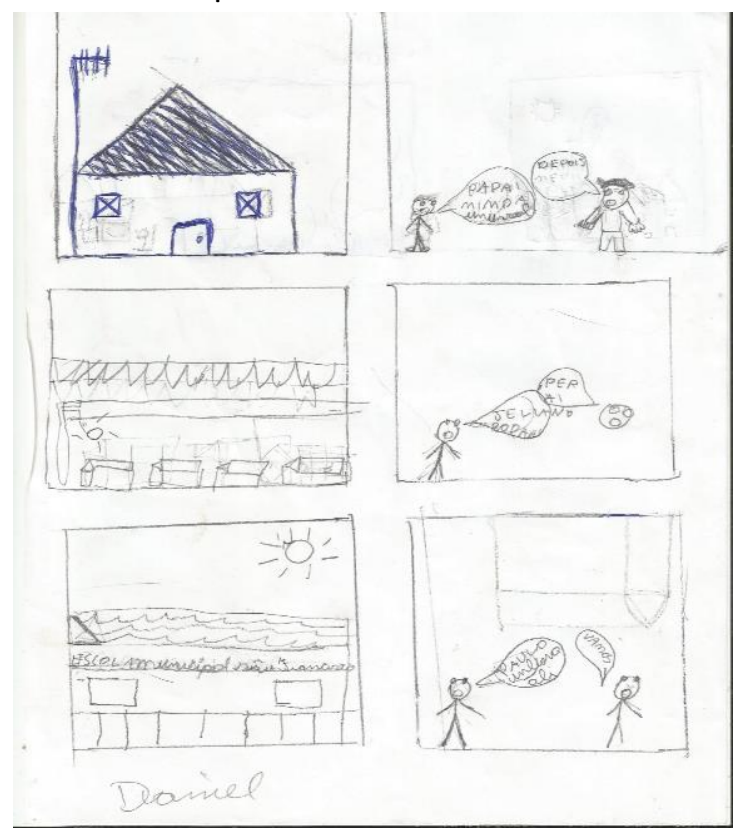

Fonte: Arquivo pessoal do autor (2017).

As possibilidades de criatividades das crianças são infinitas, mas precisam ser orientadas pelos professores e responsáveis pela criança em casa. Esta comunicação entre escola e comunidade precisa ser mais próxima, e o professor necessita considerar e se inserir no mundo do estudante, para aproveitar o aprendizado das crianças construído na própria comunidade e, assim, é necessário que a sala de aula utilize atividades criativas baseadas em conceitos subsunçores, ou seja, como ponte de conhecimento para aprender novos conhecimentos.

Não-arbitrariedade quer dizer que o material potencialmente significativo se relaciona de maneira não-arbitrária com o conhecimento já existente na estrutura cognitiva do aprendiz. Ou seja, o relacionamento não é com qualquer aspecto da estrutura cognitiva, mas sim com conhecimentos especificamente relevantes, os quais Ausubel chama subsunçores. 0 conhecimento prévio serve de matriz ideacional e organizacional para a incorporação, compreensão e fixação de novos conhecimentos quando estes 


\begin{abstract}
"se ancoram" em conhecimentos especificamente relevantes (subsunçores) preexistentes na estrutura cognitiva. Novas ideias, conceitos, proposições, podem ser aprendidos significativamente (e retidos) na medida em que outras idéias, conceitos, proposições, especificamente relevantes e inclusivos estejam adequadamente claros e disponíveis na estrutura cognitiva do sujeito e funcionem como pontos de "ancoragem" aos primeiros (MOREIRA, 2011, p. 26).
\end{abstract}

Nas ancoragens de conhecimentos advindos das histórias locais, ganha relação com a escola, uma relação que precisa ser mais próxima, o espaço institucionalizado que assume a cultura do local, baseada em ideias âncoras, no diálogo com outros conhecimentos, o que possibilita trabalhar assuntos relevantes para o desenvolvimento da estrutura cognitiva da criança, o qual se dá nas interações sociais, familiares e comunitárias, que estão presentes no mundo dessas crianças.

Estas relações ajudam a criança aprender a relacionar o ensinado na escola com o ambiente de vida. A criança que consta na Figura 2 fazendo a atividade que propusemos, participava de poucas atividades na escola, estava no 4 o ano do ensino fundamental e, tudo o que os professores pediam para ela, apresentava muitas dificuldades e o professor tinha que acompanhá-la de perto, para que a atividade solicitada fosse concretizada.

A Figura 3 representa uma importante atividade para desenvolver com as crianças, de maneira interdisciplinar, em disciplinas como: Artes, Língua Portuguesa, Geografia, História e Matemática. O que foi representado por ela em sua HQs mostra uma relação entre o que é vivido e o que é aprendido na escola. Observa-se que o elemento no primeiro quadro, a casa com antena de Tv, representa seu modo de vida, demonstrando uma vida associada com o fazer cultura, mas que não é narrada. São histórias silenciadas, e com isso se tornam apenas espaços vazios, como se não houvesse o que narrar, são percepções que demoraram a fazer com que as crianças percebessem que estas histórias as fazem ser importantes e lutarem por espaços em que sejam ouvidas para exigir direitos e cidadania.

Ainda na situação apresentada na Figura 2, pode se observar uma relação simbólica entre corpo e educação, pois a criança aparece descalça, onde ao tirar a sandália, demonstra que precisa estar livre de qualquer coisa que a prenda para realizar a atividade. Assim, deve ser a escola, livre das amarras da educação rural, lembrando que a Educação do Campo, não é apenas uma crítica, mas prática 
existencial e filosófica, criada nos movimentos sociais pelos camponeses, que sentiram a necessidade de transformação. $E$, para que haja mudanças é necessária uma educação que se desprenda das angústias da escolinha rural em que a criança tenha a liberdade e criatividade para construir sua própria existência.

\section{Representações das histórias locais nas HQs construídas pelas crianças}

A criança aprende no contato sociointeracionista com o lugar de vida, com as pessoas que fazem o lugar existir, no diálogo constante, o que possibilita ao professor conhecer as realidades dos alunos e das comunidades do Assentamento.

São relações cotidianas que realizam a educação cultural junto com o trabalho, são vidas que se conectam com o local de existência, a terra, a floresta e as águas, que dão significado à existência humana, e a escola não pode ser apenas o lugar da instrução como é compreendida na Educação Rural.

A construção da percepção do olhar da criança sobre o local de vida é essencial para que não entenda que existir no local é natural, mas construções sociais, culturais e da própria natureza, compreendendo as relações entrelaçadas da ação antrópica sobre o ambiente natural. Essa relação construída através também de memórias individuais e coletivas que infelizmente são silenciadas ou ficam no silêncio daqueles que viveram esses momentos (POLLAK, 1989).

A relação com a terra precisa sempre estar presente na Escola do Campo, esse pertencimento resulta de diálogos com a terra que é construído em relações íntimas com o local de vida, composto por terra, florestas e rios. Essas relações e conhecimentos formam a educação dos sujeitos, são historicidades presentes nas comunidades em que residem, vividas e significadas nas relações sociais que estabelecem. Segundo Caldart (2004, p. 101),

[...] nossa escola pode ajudar a perceber a historicidade do cultivo da terra e da sociedade, o manuseio cuidadoso da terra - natureza - para garantir mais vida, a educação ambiental, o aprendizado da paciência de semear e colher no tempo certo, o exercício da persistência diante dos entraves das intempéries e dos que se julgam senhores do tempo. Mas não fará isso apenas com discurso; terá que desafiar a envolver os educandos e as educadoras em atividades diretamente ligadas à terra. 
A Figura 4 representa a concepção de educação do campo que as escolas precisam praticar no cotidiano, partindo de atividades que relacionem o próprio local de vida das crianças, para que possam aprender de maneira significativa problematizando seu ambiente de vida, a partir da historicidade de suas vidas e das pessoas que vivem no contexto social no Assentamento.

Figura 4 - Representação da comunidade em HQs.

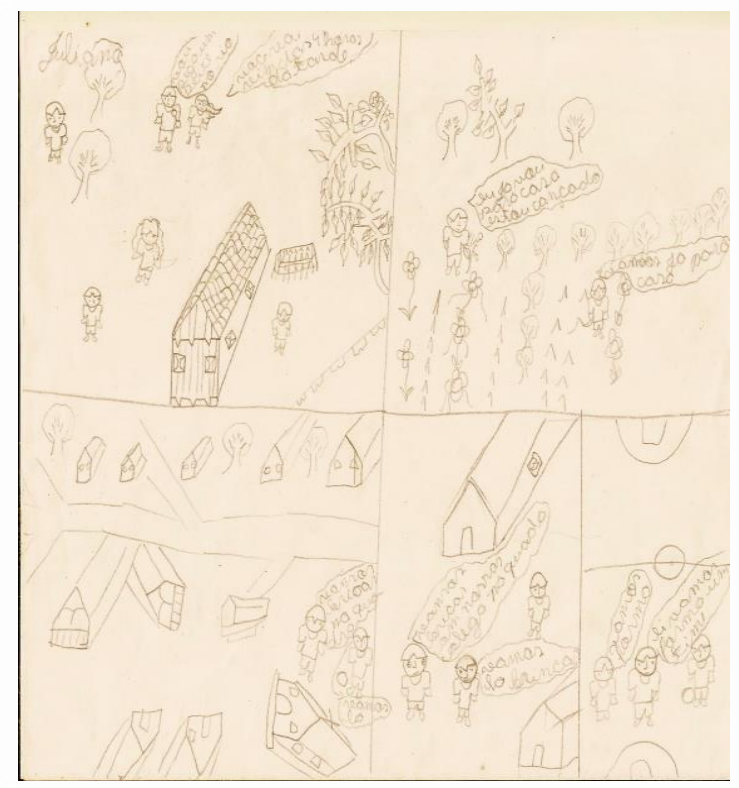

Fonte: Arquivo pessoal do autor (2017).

A escola precisa dialogar mais com a historicidade da localidade, para que a terra seja uma relação íntima com a escola, as comunidades em que as crianças vivem e possuem relação direta com o plantio, com a coleta dos frutos, caça de animais para alimento, o rio que serve para saciar a sede, para o alimento e transporte. São relações em que os mais velhos mantêm um respeito com a natureza, por meio das lendas, do misticismo que faz parte do cotidiano dessas pessoas e da historicidade de cada sujeito existente no Assentamento. Para Caldart (2004, p. 103), essas relações brotam nas existências sociais com a história do lugar.

Ela brota do cultivo da memória e da compreensão do sentido da história e da percepção de ser parte dela, não apenas como resgate de significados, mas como algo a ser cultivado e produzido. A memória coletiva é fundamental para a construção de uma identidade. 
Os significados são construídos coletivamente nas comunidades: Santo Antônio do Tracajá e Mato Grosso. As crianças são educadas no processo de memórias que são contadas e vividas nos espaços coletivos e familiares existentes nessas comunidades em que se dá a formação educacional e cultural dos sujeitos, construindo identidades de vida.

\section{Considerações finais}

A construção da educação do campo no Assentamento de Vila Amazônia está sendo um processo de mudança de concepções educacionais na interrelação imbricada por um currículo que interaja com as culturas, identidades e trabalho das comunidades. Esse processo ocorre com os próprios sujeitos que vivem, moram, trabalham nestas localidades, cujas vozes aparecem dentro das escolas e devem ser meios para colocarem, de maneira democrática, os anseios que a comunidade tem. Nesse sentido, é necessário que sejam trabalhados de maneira científica nas escolas, os arranjos locais de forma que a escola seja um espaço desse tipo de ação. Para tanto, aos professores que atuam nessas comunidades cabe conhecer mais as culturas e os meios de trabalho dos sujeitos assentados.

O trabalho na sala de aula sobre histórias locais é uma didática que pode enriquecer o ambiente escolar e da comunidade, em que ambos podem perceber que suas relações constroem o local em uma relação mútua de diálogos culturais, científicos e escolares, oportunizando à criança ter sentimentos de pertencimento com a comunidade em que vive. Essa relação pode possibilitar uma educação escolar que mostre ao aluno viabilidades de permanecer na própria comunidade e transformar sua realidade e de seus familiares, bem como da comunidade, a partir do conhecimento científico que possibilite desenvolver o conhecimento agrário. Hoje as escolas do Assentamento não possuem esse tipo de conhecimento no currículo escolar, sendo necessário que as escolas do campo tenham disciplinas que abordem esse conhecimento nas aulas, pois as crianças e seus pais, em sua grande maioria, estão vindo para a cidade em busca de uma vida melhor, e, um dos meios para incentivar as famílias a permanecerem no campo é uma escola que trabalhe os saberes da terra, agrários e da pesca. 
A escola do campo está em um movimento que inclua o cotidiano das pessoas, uma escola que não tenha apenas discursos utilizados em encontros pedagógicos organizados. Entende-se que, os professores precisam sentir o desejo de transformar a vida das pessoas por meio de uma educação que considere a essência do local em que é realizada. A educação do campo necessita simbolizar a existência do mundo social dessas comunidades, propiciando às crianças uma formação que priorize a emancipação social, para que protagonizem seus sonhos, e caminhem agindo com autonomia e cidadania.

O espaço escolar precisa ser um local de sonhos realizáveis, que todos sintam a mobilização de práticas existenciais acontecer, e que seja planejada a partir do diálogo construído nas bases da comunidade, com a participação de todos, desde o mais novo ao mais velho, sem exceções. Esses espaços carecem de infraestrutura que integre as escolas com espaços comunitários. No entanto, em sua maioria, a percepção existencial da didática nas escolas pesquisadas não mostra que reconhecem o quanto precisam dialogar com os ambientes de vida das crianças e com as culturas que permeiam esses locais.

Existem nesses espaços muitas formas de vivências que não são narradas e muito menos registradas, em que as crianças vão perdendo oportunidades identitárias de conhecer suas próprias origens. As atividades propostas neste estudo por meio HQs incentivam a escola perceber e tornar as histórias de vida dos alunos audíveis nos espaços escolares, transformação essa que precisa existir a partir dos docentes que atuam nessas escolas, para que possam transformar e tornar a escola "no" campo em escola "do" campo.

\section{Referências}

ALBERTI, Verena. Tratamento das entrevistas de história oral no CPDOC. Rio de Janeiro: CPDOC, 2005.

ARROYO, Miguel G. Os movimentos sociais e a construção de outros currículos.

Educar em Revista, n. 55, p. 47-68, 2015. Disponível em:

https://www.scielo.br/pdf/er/n55/0101-4358-er-55-00047.pdf. Acesso em: 05 mai. 2020. 
ARROYO, Miguel Gonzalez. A Educação Básica e o Movimento social do Campo. In: ARROYO, Miguel Gonzalez; CALDART, Roseli Salete; MOLINA, Mônica Castagna (org.). Por uma educação do campo. Petrópolis, RJ: Vozes, 2004.

BRASIL. Lei no 9.394, de 20 de dezembro de 1996. Estabelece as diretrizes e bases da educação nacional. Brasília, DF: Presidência da República, 1996. Disponível em: http://www.planalto.gov.br/ccivil_03/leis/I9394.htm. Acesso em: 16 mar. 2020.

BRASIL. Ministério da Educação. Secretaria de Educação Básica. Base Nacional Comum Curricular: 2018. Brasília: MEC/SEB, 2018. Disponível em: http://basenacionalcomum.mec.gov.br/. Acesso em: 05 mai. 2020.

CALDART, Roseli Salete. Por uma Educação do Campo: traços de uma identidade em construção. In: ARROYO, Miguel Gonzalez; CALDART, Roseli Salete; MOLINA, Mônica Castagna (org.). Por uma educação do campo. Petrópolis, RJ: Vozes, 2004.

CERBONE, David R. Fenomenologia. Petrópolis, Rj: Vozes, 2012.

CORRÊA, Sérgio Roberto Moraes. "Currículos" e saberes: caminhos para uma educação no campo multicultural na Amazônia. In: HAGE, Salomão Mufarry (org.). Educação do campo na Amazônia: retratos de realidade das escolas multisseriadas no Pará. Belém: Gráfica e Editora Gutemberg Ltda, 2005.

FREIRE, Paulo. Pedagogia da autonomia: saberes necessários à prática educativa. São Paulo: Paz e Terra, 1996.

MEDEIROS, Mônica Xavier de. Puxirum de histórias: lutas por terras e águas em Vila Amazônia/Parintins (1980-2000). 2017. 275 p. Tese (Doutorado em História Social). Pontifícia Universidade de Católica de São Paulo. São Paulo: PUC, 2017.

MERLEAU-PONTY, Maurice. Fenomenologia da percepção. 3. ed. São Paulo: Martins Fontes, 2014.

MOREIRA, M. A. Aprendizagem significativa: um conceito subjacente. In: ACTAS DEL ENCUENTRO INTERNACIONAL SOBRE EL APRENDIZAJE SIGNIFICATIVO, 1., 1997, Burgos. Anais [...]. Burgos, España: Universidade de Burgos, 1997.

POLLAK, Michael. Memória, esquecimento, silêncio. Revista Estudos Históricos, Rio de Janeiro, v. 2, n. 3, p. 3-15, jun. 1989. Disponível em: http://bibliotecadigital.fgv.br/ojs/index.php/reh/article/view/2278. Acesso em: 28 nov. 2018. 
SANTOS NETO, Elydio dos; SILVA, Marta Regina da (org.). Histórias em quadrinhos e práticas educativas: os gibis estão na escola, e agora?. 2. ed. São Paulo: Criativo, 2015.

SILVEIRA, Éder da Silva. História oral e memória: pensando um perfil de historiador etnográfico. MÉTIS: História \& Cultura, v. 6, n. 12. p. 35-44, jul./dez. 2007.

VERGUEIRO, Waldomiro. A linguagem dos quadrinhos: uma "alfabetização necessária. In: VERGUEIRO, Waldomiro (org). Como usar as histórias em quadrinhos na sala de aula. 4. ed. São Paulo: Contexto, 2014.

Enviado em: 23/06/2019

Aprovado em: 16/04/2020 